\title{
Treatment of Androgen-Independent Prostate Cancer Using Antimicrotubule Agents Docetaxel and Estramustine in Combination: An Experimental Study
}

\author{
Jeffrey F. Williams, ${ }^{1}$ Heather J. Muenchen, ${ }^{1}$ Jeffrey M. Kamradt, ${ }^{1}$ \\ Susan Korenchuk, ${ }^{1}$ and Kenneth J. Pienta ${ }^{1,2 *}$ \\ 'Division of Hematology/Oncology, Department of Internal Medicine, University of \\ Michigan, Ann Arbor, Michigan \\ ${ }^{2}$ Division of Urology, Department of Surgery, University of Michigan, Ann Arbor, Michigan
}

\begin{abstract}
BACKGROUND. Estramustine in combination with other chemotherapeutic agents has demonstrated synergy in hormone-refractory prostate cancer. Docetaxel has demonstrated antineoplastic activity in a variety of chemotherapeutic-unresponsive tumors. We evaluated the effects of estramustine and docetaxel in preclinical models of prostate cancer.

METHODS. Cell viability of PC-3 and MAT-LyLu (MLL) cells were assessed $48 \mathrm{hr}$ after drug treatment. For in vivo studies, each flank of five animals in six groups was injected with $1 \times$ $10^{6}$ MLL cells: control, estramustine, docetaxel (low- and high-dose), and low- and high-dose docetaxel with estramustine. Animals were treated on days 4 and 11, and sacrificed on day 14 . RESULTS. The $\mathrm{IC}_{50}$ value for docetaxel was $2 \mathrm{nM}$ in the PC-3 cells and $40 \mathrm{nM}$ in the MLL cells. The addition of $100 \mathrm{nM}$ of estramustine did not alter the $\mathrm{IC}_{50}$ value for PC-3 cells. In the MLL cells, however, the $\mathrm{IC}_{50}$ value was lowered to $15 \mathrm{nM}$. In vivo, low-dose docetaxel with estramustine demonstrated antineoplastic activity similar to that of high-dose docetaxel alone, suggesting additive activity between the drugs.

CONCLUSIONS. These results demonstrate that when used in combination, docetaxel and estramustine can be more effective at lower dosages than when the individual drugs are used alone. Prostate 44:275-278, 2000. @ 2000 Wiley-Liss, Inc.
\end{abstract}

KEY WORDS: docetaxel; estramustine; MLL; PC-3; prostate

\section{INTRODUCTION}

Prostate cancer is the most common malignancy diagnosed in men, and the second leading cause of death in American males [1]. There are limited treatment options, and prognosis continues to be dismal in metastatic hormone-refractory prostate disease. In newly diagnosed metastatic disease, hormone therapy controls symptoms in $80-90 \%$ of patients. The median duration of response is approximately $2-3$ years. Chemotherapy is the next option; however, the response induced by chemotherapy is generally limited and of short duration, with an overall objective response of $8.7 \%$ for single agents and approximately $50 \%$ for newer regimens. Cancer patients are often debilitated or immunocompromised and, therefore, chemotherapy is not always feasible or well-tolerated [2].
Treatment of metastatic disease is considered palliative, since no chemotherapeutic regimen has shown a survival benefit in a randomized clinical trial. Due to these limitations, new agents and strategies clearly needed.

Estramustine phosphate (Emcyt, Estracyt), a nonnitrogen mustard carbamate, binds to microtubuleassociated proteins, inhibits assembly, and disrupts

Grant sponsor: CaPCURE; Grant number: SPORE P50 CA69568; Grant sponsor: Rhone-Poulenc Rorer.

${ }^{*}$ Correspondence to: Kenneth J. Pienta, M.D., Department of Internal Medicine, University of Michigan Medical School, 1500 East Medical Center Dr., 7303 CCGC, Ann Arbor, MI 48109-9480. E-mail: kpienta@umich.edu

Received 6 December 1999; Accepted 10 April 2000 


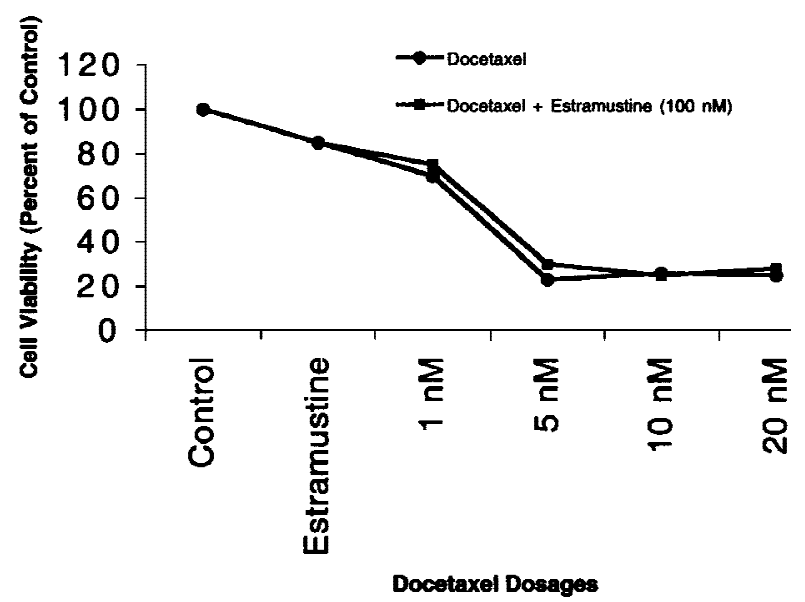

Fig. I. In vitro analysis of PC-3 cells treated with Taxotere demonstrated an $\mathrm{IC}_{50}$ value of approximately $2 \mathrm{nM}$. The addition of Emcyt (I00 nM) did not significantly alter this $I C_{50}$ value.

microtubule organization in vitro [3]. It is this cellular mechanism, and not the hormonal effect associated with the estrogen moiety or alkylating activity due to nitrogen mustard, that is responsible for the cytotoxic effects of estramustine in hormone-refractory prostate cancer [3]. Estramustine has also been shown to reduce the level of serum prostate-specific antigen (PSA) [4].

Docetaxel (Taxotere), a member of the taxane family, binds to tubulin, promoting microtubule assembly and microtubule bundling $[5,6]$. Like other members of the taxane family, docetaxel stabilizes spindle microtubules, impairing mitosis and blocking progression through the cell cycle [5]. It demonstrates significantly longer cellular affinity and uptake, and slower cellular efflux than paclitaxel, which prolongs the duration of cell drug exposure [7]. Docetaxel is also approximately twice as efficient as paclitaxel in stabilizing microtubules [8].

Estramustine in combination with other chemotherapeutic agents has demonstrated synergy in hormone-refractory prostate cancer. Docetaxel has demonstrated antineoplastic activity in a variety of previously chemotherapeutic-unresponsive tumors. We here evaluated the in vitro and in vivo effects of estramustine and docetaxel in preclinical models of prostate cancer.

\section{MATERIALS AND METHODS}

\section{Drugs and Reagents}

Estramustine phosphate (estradiol-3-N-bis-[2chloroethy]-carbamate-17-beta-dihydrogen disodium phosphate) was purchased from Hoffmann-LaRoche (Nutley, NJ). Docetaxel (Taxotere) was purchased from Rhone-Poulenc Rorer (Collegeville, PA) as a prepared sterile stock solution of $10 \mathrm{mg} / \mathrm{ml}$.

\section{Cell Culture}

The prostate adenocarcinoma cell line PC-3 (American Type Culture Collection, Rockville, MD) and the metastatic MAT-LyLu (MLL) subline of the Dunning R-3327 rat prostate adenocarcinoma line were grown and maintained at $37^{\circ} \mathrm{C}$ in an atmosphere of $5 \% \mathrm{CO}_{2}$ in RPMI-1640 medium (Life Technologies, Grand Island, NY) containing 1\% antibiotic-antimycotic (penicillin G, 10,000 U/ml; streptomycin sulfate, $10,000 \mu \mathrm{g} / \mathrm{ml}$; and amphotericin B, $25 \mu \mathrm{g} / \mathrm{ml}$ ) (Life Technologies) and supplemented with $10 \%$ fetal bovine serum (Life Technologies). Stock drug was added to the cell culture medium to reach the reported concentrations.

\section{Cell Growth and In Vitro Cytotoxicity Assay}

Cell adhesion was used as a marker of cell viability. At hr $0,2 \times 10^{5}$ PC-3 and MLL cells, per T25 flask, were plated in triplicate. At hr 48, increasing doses of docetaxel alone, as well as in combination with $+100 \mathrm{nM}$ estramustine, were added to the flasks. After an additional $48 \mathrm{hr}$ of incubation, the cells were lysed and the nuclei counted (Z1 Coulter Counter, Coulter, Hialeah, FL).

\section{Animals}

Male Copenhagen rats were obtained from Harlan Sprague-Dawley (Indianapolis, IN). Methoxyflurane (Pittman-Moore, Washington Crossing, NJ) was used as inhalation anesthetic for injections and surgical procedures.

\section{In Vivo Animal Tumor Model}

Animals, 5 per group, were injected with $1 \times 10^{6}$ MLL cells subcutaneously into each flank on day 0 . There were 5 rats per treatment and control group, respectively.

Treatment groups consisted of the following: 1) control, 2) estramustine $(7 \mathrm{mg} / \mathrm{kg}), 3)$ low-dose docetaxel $(7 \mathrm{mg} / \mathrm{kg}), 4)$ high-dose docetaxel $(11.6 \mathrm{mg} / \mathrm{kg})$, 5) low-dose docetaxel and estramustine, and 6) highdose docetaxel and estramustine.

On day 0 , animals were injected with $1 \times 10^{6}$ MLL cells in each flank. On days 4 and 11, animals were given intraperitoneal injections of the drugs. On day 14, animals were sacrificed, the tumors were harvested, and the tumor weights were noted. Paired Student's $t$-test was used to compare control and treatment groups. 
Fig. 2. MLL cells treated with Taxotere in vitro had an $I_{50}$ value of $40 \mathrm{nM}$. The addition of Emcyt (I00 nM) lowered this value to approximately $15 \mathrm{nM}$.

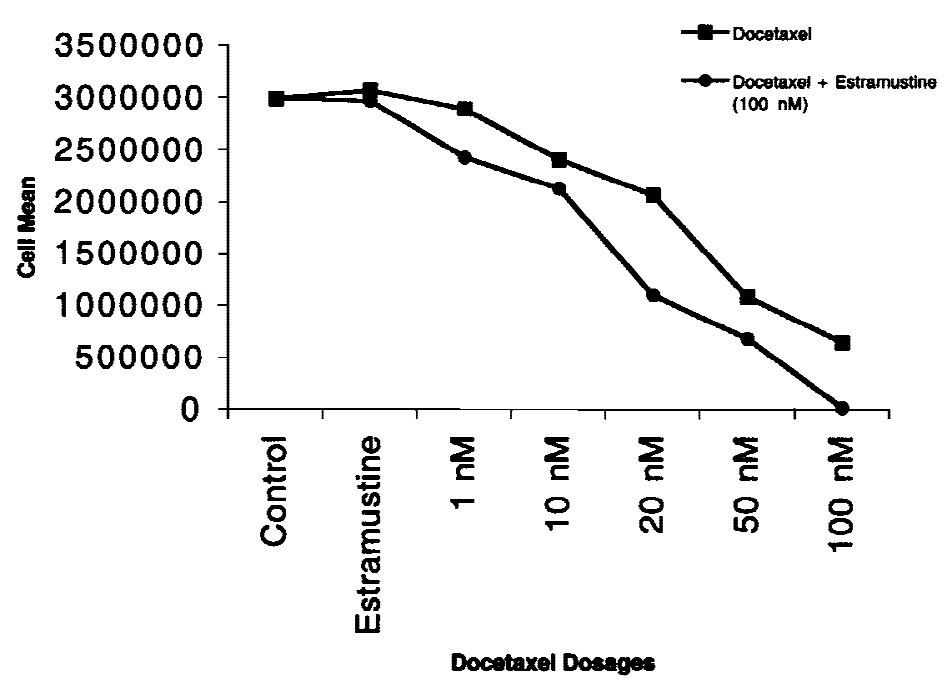

duction in the required dosages of individual drugs and potentially decreased toxic side effects is another advantage of using these combination therapies.

Estramustine has been shown to bind to microtubule-associated proteins and disrupt microtubule organization in vitro $[9,10]$. Estramustine is currently indicated in the palliative treatment of patients with metastatic and/or progressive prostate cancer, with a response rate of $5-17 \%$ as a single agent [11]. Its toxicities include fluid overload and thrombophlebitis.

Docetaxel, a semisynthetic taxoid, interferes with the microtubular network essential for mitotic and interphase cellular functions $[12,13]$. It binds to free tubulin and promotes the assembly of stable microtubules that cannot disassemble [12]. As a single agent, it has been shown to be effective in chemoresistant breast cancer [14]. Bone marrow suppression is a major dose-limiting toxicity.

Combining agents that are active against a particular tumor but do not have overlapping toxicities has been a basic rule in clinical oncology. In patients with prostate cancer, this has not been the case. Preclinical studies demonstrated that a single-agent estramustine (noneffective as a single agent) and docetaxel (noneffective as a single agent) demonstrated synergistic activity, and the combination of the two agents was clinically much more effective than when either agent was given alone [15].

A phase I trial evaluated Emcyt and Taxotere [16]. The regimen consisted of Emcyt $280 \mathrm{mg}$ PO TID days $1-5$, Taxotere 40,60 , or $70 \mathrm{mg} / \mathrm{m}^{2}$, and Decadron 20 $\mathrm{mg} 6+12 \mathrm{hr}$, and $15 \mathrm{~min}$ prior to Taxotere on day 2 . The cycle was repeated every 21 days. The overall response rate was $62 \%$, as defined by a PSA decrease of at least $50 \%$. Of the responders, $69 \%$ failed steroids and $54 \%$ failed Emcyt. Forty-three percent of patients with measurable disease had a partial response. The 


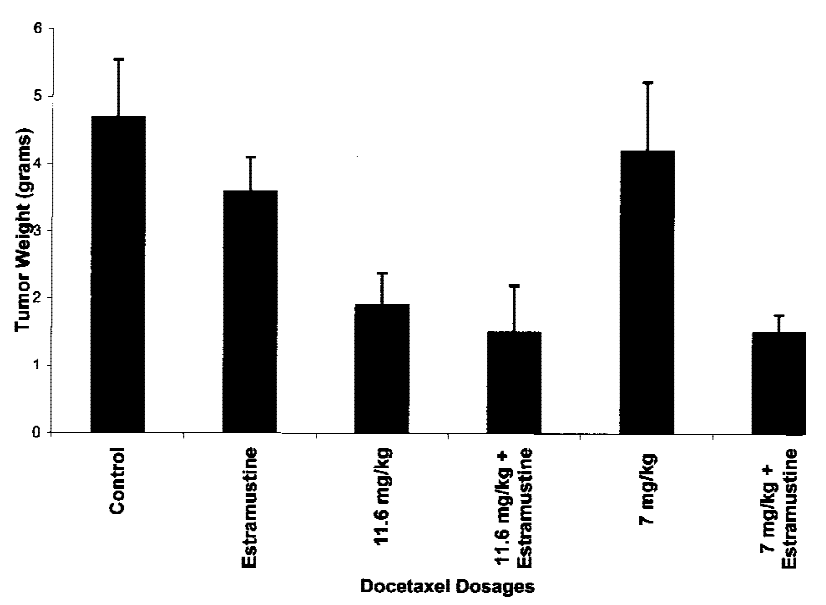

Fig. 3. In vivo study, demonstrating a decrease in tumor mass of mice treated with Taxotere $(11.6 \mathrm{mg} / \mathrm{kg})$ alone. The addition of Emcyt (100 nM) significantly lowered the tumor mass in mice treated with low-dose Taxotere $(7 \mathrm{mg} / \mathrm{kg})$, but not high-dose Taxotere (I $1.6 \mathrm{mg} / \mathrm{kg})$, suggesting an additive effect in the latter.

toxicities included fluid retention, granulocytopenia, and hepatotoxicity.

Another phase I/II trial by Kreis in 1999 [15] again involved Emcyt and Taxotere. The regimen consisted of Emcyt $140 \mathrm{mg} / 10 \mathrm{~kg}$ body weight PO QD, Taxotere 40,60 , or $80 \mathrm{mg} / \mathrm{m}^{2}$, and Decadron $8 \mathrm{mg}$ BID $\times 5$ doses. The cycle was repeated every 21 days. Nine patients in total were enrolled. Four patients had at least a 50\% decrease in PSA. The toxicities included esophageal dyspepsia, nausea, and diarrhea.

Our results demonstrate that docetaxel and estramustine have a significant cytotoxic effect in the PC-3 and MAT-LyLu prostatic cell lines. We demonstrated enhanced cytotoxic effects when these drugs were used in combination, both in vitro and in vivo, with MLL cells. These results are similar to those reported by other authors using combinations of these agents.

\section{CONCLUSIONS}

In vitro, docetaxel has significant cytotoxic activity. This effect was also demonstrated in vivo in this study. The addition of estramustine did not enhance this effect in vitro in the PC-3 cell line, but was significant in MLL cells. In vivo studies demonstrated a significant decrease in tumor weight of mice treated with either low- or high-dose docetaxel in combination with estramustine.

\section{REFERENCES}

1. Smith D, Pienta K. Paclitaxel in the treatment if hormonerefractory prostate cancer. Semin Oncol 1999;26:109-111.

2. Yagoda A, Petrylak D. Cytotoxic chemotherapy for advanced hormone resistant prostate cancer. Cancer 1993;71:1098-1109.

3. Stears M, Wang M, Tew K, Binder L. Estramustine binds a MAP-1 like protein to inhibit microtubule assembly in vitro and disrupts microtubule organization in DU 145 cells. J Cell Biol 1988;107:2647-2652.

4. Ringel I, Horwitz S. Studies with RP 56976 (Taxotere): a semisynthetic analogue of taxol. J Natl Cancer Inst 1991;83:288-291.

5. Schiff PB, Horowitz SB. Taxol stabilizes microtubules in mouse fibroblast cells. Proc Natl Acad Sci USA 1980;77:1561-1565.

6. Caplow M, Shanks J, Ruhlen R. How taxol modulates microtubule disassembly. J Biol Chem 1994;269:23399-23402.

7. Riou J, Petitgenet O, Combeau C. Cellular uptake and efflux of docetaxel (Taxotere) and paclitaxel (Taxol) in P388 cell line. Proc Am Assoc Cancer Res 1994;35:385.

8. Diaz J, Andreu J. Assembly of purified GDP-tubulin into microtubules induced by taxol and taxotere: reversibility, ligand stoichiometry, and competition. Biochemistry 1993;32:2747-2755.

9. Stearns M, Tew K. Antimicrotubule effects of estramustine, an antiprostatic tumor drug. Cancer Res 1985;45:3891-3897.

10. Dahllof B, Billstrom A, Cabral F, Hartley-Asp B. Estramustine depolymerizes microtubules by binding to tubulin. Cancer Res 1993;53:4573-4581.

11. Roth B. Combination chemotherapy in advanced prostate cancer: a silk purse? Clin Oncol 1994;12:2001-2002.

12. Jordan M, Toso R, Thrower D, Wilson L. Mechanisms of mitotic block and inhibition of cell proliferation by Taxol at low concentrations. Proc Natl Acad Sci USA 1993;90:9552-9556.

13. Jordan M, Wendell K, Gardiner S, Derry W, Copp H, Wilson L. Mitotic block induced in HeLa cells by low concentrations of paclitaxel (Taxol) results in abnormal mitotic exit and apoptotic cell death. Cancer Res 1996;56:816-825.

14. Miller K, McCaskill-Stevens W, Sisk J, Loesch D, Monaco F, Seshadri R, Sledge G Jr. Combination versus sequential doxorubicin and docetaxel as primary chemotherapy for breast cancer; a randomized pilot trial of the Hoosier Oncology Group. Clin Oncol 1999;17:3033-3037.

15. Kreis W, Budman D, Fetten J, Gonzales A, Barile B, Vinciguerra V. Phase II trial of the combination of daily estramustine phosphate and intermittent docetaxel in patients with metastatic hormone refractory prostate carcinoma. Ann Oncol 1999;10:33-38.

16. Petrylak D, Macarthur R, O'Connor J, Shelton G, Judge T, Balog J, Pfaff C, Bagiella E, Heitjan D, Fine R. Phase I trial of docetaxel with estramustine in androgen-independent prostate cancer. Clin Oncol 1999;17:958-967. 